Article

\title{
Interval-Parameter Two-Stage Stochastic Programming (IPTSP) Model of Ecological Water Replenishment Scheme in the National Nature Reserve for Improved Suitable Habitat for Rare and Endangered Migrant Birds
}

\author{
Xianrui Liao ${ }^{1}$, Chong Meng ${ }^{2}$, Baofeng Cai ${ }^{1}$ and Wenjin Zhao ${ }^{1, *}$ \\ 1 College of New Energy and Environment, Jilin University, Changchun 130012, China; \\ liaoxr18@mails.jlu.edu.cn (X.L.); cbf777@sohu.com (B.C.) \\ 2 College of Environment, Beijing Normal University, Beijing 102206, China; meng@bnu.edu.cn \\ * Correspondence: zhaowj@jlu.edu.cn; Tel.: +86-133-4158-2727
}

Received: 15 April 2020; Accepted: 22 May 2020; Published: 26 May 2020

check for updates

\begin{abstract}
In this work, an interval-parameter two-stage stochastic programming (IPTSP) model of water resources allocation was established for maximizing the restored habitat area of large, rare, and endangered water birds by adjusting the recommended scheme of water replenishment under different scenarios and constraints. The established model can efficiently deal with the uncertainties, such as the interval parameters and random variables, in the management system of water resources simultaneously. A case study was conducted in the Momoge National Nature Reserve (MNNR) in northeast China to maximize the restored habitat area of large, rare and endangered water birds based on limited water resources. According to the previous studies, a water area with a depth of $0-40 \mathrm{~cm}$ is a suitable habitat area in the MNNR for the Siberian crane, oriental stork, and red-crowned crane. The results of the present work show that the habitat area restored by water replenishment schemes under low, medium, and high flood flow scenarios after optimization increased in comparison to $13.36 \times 10^{3}$ ha of the recommended scheme, with an increase of $[0.62,5.23]$, $[1.49,6.42]$, and $[2.43,7.17] \times 10^{3}$ ha, respectively (the two numbers within each bracket represent the lower and upper bounds of the restored habitat areas). As a result, the carrying capacity of suitable habitat areas increased by $[0.82,6.88],[1.96,8.45]$, and $[3.21,9.43] \times 10^{3}$ birds, correspondingly. The restored wetland area of the project recommendation scheme was $34.23 \times 10^{3}$ ha, and that of the optimal water replenishment schemes was [29.35, 41.01], [31.02, 44.13], and [33.88, 46.04] $\times 10^{3}$ ha, respectively under the three flood flow scenarios. The results reveal that the model constructed in this work realizes the optimization and adjustment of the initial scheme to an increased restored wetland and habitat area with an increase in the flow level. Here, the upper bound of the interval value mentioned above is significantly higher than the lower bound value, which indicates that a feasible decision space was provided for decision makers to optimize and adjust the recommended scheme on the basis of the actual situation. The model-optimized schemes significantly improved the utilization of limited water resources. The results of this study can provide valuable theoretical support for the restoration and protection of rare and endangered water bird habitats and planning and management of water resources.
\end{abstract}

Keywords: wetland in the nature reserve; rare and endangered water birds; habitat area; interval-parameter two-stage stochastic programming; water resource allocation 


\section{Introduction}

A wetland is known as the "kidney of the earth" that not only provides important ecological services such as material production, flood control, water storage, pollution degradation, and climate regulation [1-4], but also is an important habitat and breeding ground for rare and endangered water birds [5]. The Momoge National Nature Reserve (MNNR) in the Jilin Province of China is an important stopover site for large, rare and endangered water birds such as the Siberian crane (Grus leucogeranus), oriental stork (Ciconia boyciana), and red-crowned crane (Grus japonensis) [6]. Affected by natural factors such as climate change and man-made development and construction activities, the wetland area in the MNNR has been greatly reduced due to water shortage. As a result, the suitable habitat area for the endangered water birds has been decimated, resulting in a sharp decline in their numbers [7].

The study species have been listed as threatened species on the "red list" of the International Union for Conservation of Nature (IUCN) and are also the First-Grade State Protection animals in China. These are large water birds that depend on shallow wetlands for their survival. Water depth is the most important factor limiting the use of a habitat area by water birds [8,9]. The water depth can determine whether a habitat can be used by the water birds [10], and it also affects their feeding behavior and feeding efficiency $[11,12]$. The study species are wading birds, unable to reach and use deep-water habitats. They generally live in marshes or shallow water areas having a water depth below their tarsus $(40 \mathrm{~cm})$ [13-16]. Further, due to the limitations of their body size, especially the length of their beak, legs, and neck, they generally feed in shallow water areas having a depth of less than $40 \mathrm{~cm}$, such as reed marshes and fish ponds [15-18]. Further, they cannot survive in regions with very less water, as they need to put much effort to find food or cannot peck out food at all [14]. The depth of water in an area can also affect the selection and use of habitat by the water birds by affecting the distribution of food resources $[19,20]$. The maximum species abundance usually occurs in shallow water areas of wetlands [21] that are rich in food resources. The bulb of Scirpus planiculmis is the main food of the Siberian cranes in the MNNR [22], which has a strong growth and reproduction capacity in the water area of $0-30 \mathrm{~cm} \mathrm{[23]} \mathrm{and} \mathrm{its} \mathrm{optimal} \mathrm{growth} \mathrm{depth} \mathrm{is} 20-30 \mathrm{~cm}$. When the water depth is more than $30 \mathrm{~cm}$, its density begins to decrease. In a water area having a depth of more than $40 \mathrm{~cm}$, it is completely replaced by reeds and papyrus [24,25]. Oriental storks mainly feed on fish, while red-crowned cranes are omnivorous birds mainly feeding on snails and shellfish in the MNNR. A wetland area with a water depth of $0-40 \mathrm{~cm}$ can provide sufficient food resources and a suitable habitat area for the study species. Therefore, increasing the wetland area with a water depth of $0-40 \mathrm{~cm}$ can increase the habitat area of large rare and endangered water birds, which is conducive to their population increase. At present, many studies on such habitats for endangered water birds such as the Siberian crane have focused mainly on the assessment of habitat suitability [26-28], habitat selection [24,29], habitat impact factors [5,14,18,22,30], and so on, which mainly involves studies on the existing habitats. However, there are few studies on the restoration of habitat areas based on practice. At the same time, most of these studies consider only a single species $[22,26,27]$, and only a few consider multiple species simultaneously.

Ecological water replenishment is one of the most efficient and direct ways to restore wetland functions and rebuild the wetland ecosystem [31,32]. Wetlands represent one of the most important types of ecosystems, as they provide important ecosystem services that have an influence on the survival and development of animals and humans [33-35]. In recent decades, significant progress has been made in the study of the theory and evaluation techniques used for ecological service valve evaluation, and ecological service value has become a significant indicator of ecosystem functions [36,37]. Moreover, ecological service value can be used as an important assessment index of wetland restoration projects [38]. Thus, it is not only the restoration of the habitat areas for water birds but also other factors such as ecological service value and the water supply capacity, which should be considered in the process of ecological water replenishment for wetlands, especially in the MNNR where water resources are scarce [39]. Under such circumstances, preparing a reasonable and scientific ecological water replenishment scheme for the MNNR taking all of these factors into consideration becomes 
an important question. The system optimization model can connect the system components such as hydrology, ecology, and management, allowing managers to evaluate options for allocating scarce resources to optimize management objectives [40]. Due to its complexity, a water resource management system inevitably has some uncertain factors, including water supply and demand, flood resources, and economic parameters, and so on [41,42]. In the water resource management system of the MNNR, parameters such as the water supply capacity, planning scope of lakes, wetland ecological water demand, and the ecological benefits per unit area are often shown as the interval form fluctuating within a certain range and are difficult to express by certain numbers. Moreover, affected by rainfall and other factors, the flood resources are subject to random uncertainty, which is a significant factor affecting the water resource allocation and restoration of the wetland area of the MNNR. Different flood resource scenarios will bring forth multiple difficulties during the realization and optimization of the ecological water replenishment plan for the MNNR. The traditional deterministic model cannot deal with interval parameters and random uncertain parameters efficiently, thus resulting in non-optimal and even incorrect model results [43]. Interval programming and two-stage stochastic programming respectively can address these uncertainties. Interval programming can process the interval parameters in the system in the form of interval values [44,45], whereas a two-stage stochastic method can efficiently process random parameters in the form of a probability distribution [46,47]. The inexact two-stage stochastic programming (ITSP) coupling method constructed by Huang et al. [48] can effectively deal with both interval parameters and random variables at the same time [49], thus having been widely used. For example, Fu et al. [50] presented an ITSP model for multi-conflict regional water resources allocation in the south-to-north water benefited area. Li et al. [51] developed an interval-parameter two-stage stochastic programming model for supporting sustainable water resources planning in Zhengzhou City, China. Meng et al. [52] proposed an ITSP model for supporting water resources allocation and total amount control of the pollutant emissions in the Yinma River Basin in northeast China.

Therefore, in this work, an optimal allocation model of water resources was constructed based on the interval-parameter two-stage stochastic programming (IPTSP) method for maximizing the restored habitat area of rare water birds. The constructed model was applied to investigate the optimization of the restored habitat area of the study species in the MNNR in the Jilin Province by optimization and adjustment of the ecological water replenishment of the recommended plan under different flood flow scenarios. The results are expected to provide advice for the administrative department to make scientific and effective water replenishment schemes, thus improving the utilization of limited water resources.

\section{Case Study}

The project involved in the recommended scheme is located on the right bank of the Nenjiang River and the plain on the left bank of the Songhua River, covering eight counties, including Zhenlai county. The study area of the MNNR is located in the southeast of Zhenlai county, Baicheng. The reserve is rich in biological species, and a wetland reserve takes in rare water birds such as cranes and storks and conserves their habitats as protected objects [53]. The MNNR is not only an important habitat and migration station for these endangered water birds, but is also the largest stopover site in the world for the Siberian cranes. At its peak, 3800 Siberian cranes were detected in the MNNR, accounting for more than $95 \%$ of the world's population of this species [54]. Their rest time in the MNNR has also been observed to be the longest. Therefore, the MNNR is of great international significance for the protection of global biodiversity.

There has been a shortage of water resources in the MNNR. This is because the annual rainfall in the region is less than $400 \mathrm{~mm}$. However, the annual evaporation is up to $900-1000 \mathrm{~mm}$. In addition, the distribution of precipitation is very uneven and is mainly concentrated between the months of June and August. The lack of natural precipitation in the reserve, combined with wetland reclamation and the construction of water conservancy projects and roads, has brought about a substantial shrinking and degradation of the wetland area, a decline in the ecological function of the wetland, and drying up of some lakes. As a result, shrinking and fragmentation of the habitat area, on which Siberian cranes 
and other large rare water birds rely for survival and breeding, were exacerbated, and the population of the protected birds that come here to live and breed has decreased. The population of the Siberian crane in the MNNR was more than 2000 from 2004 to 2011 [24], reaching a peak of 3800 in 2012 and dropping to 1800 in the autumn of 2015. Historically, the resting population of oriental storks reached 400-800, which was 40-80 in spring 2013 and 83 in 2014 [54]. Red-crowned cranes, the migrant birds, have a small population with only 10 to 20 resting population from 2009 to 2013 . The largest resting population was 22 in the autumn of 2012, while it decreased to 11 in the spring of 2013. From these numbers, it is clear that the function of the MNNR as an important stopover site on the migratory route of rare birds has been greatly reduced.

According to the project recommendation scheme, in order to restore the wetland area of the MNNR and to protect these large rare water birds, the water demand of the wetland should be met in the first place. The MNNR mainly relies on the "Yinnenrubai" water replenishment project, which connects 66 lakes via $54 \mathrm{~km}$ trunk channels and affiliated branch channels. In this work, 18 lakes in the MNNR were selected as the study areas, which are replenished by four water intakes. They are the third branch channel of the Baishatan irrigation area (BIA), Zhushan pumping station (ZPS), Shijiangfang intake gate (SIG), and Haernao pumping station (HPS), respectively. BIA supplies water to 9 lakes, including the Etou Lake. Its available normal water and flood replenishment in the project recommended scheme are $7633 \times 10^{4} \mathrm{~m}^{3} /$ year and $2997 \times 10^{4} \mathrm{~m}^{3} /$ year, respectively. ZPS supplies water to 3 lakes, including the Zhushan Lake. Its available flood replenishment is $2014 \times 10^{4} \mathrm{~m}^{3} /$ year. SIG supplies water to four lakes, including the Haernao Lake. Its available flood replenishment is $2297 \times 10^{4} \mathrm{~m}^{3} /$ year. HPS supplies water to four lakes, including the Nashi Lake and its available flood replenishment is $288 \times 10^{4} \mathrm{~m}^{3} /$ year. The project recommendation scheme would restore a wetland area of $34.23 \times 10^{3}$ ha. The geographical locations of the MNNR and 18 lakes are shown in Figure 1 .
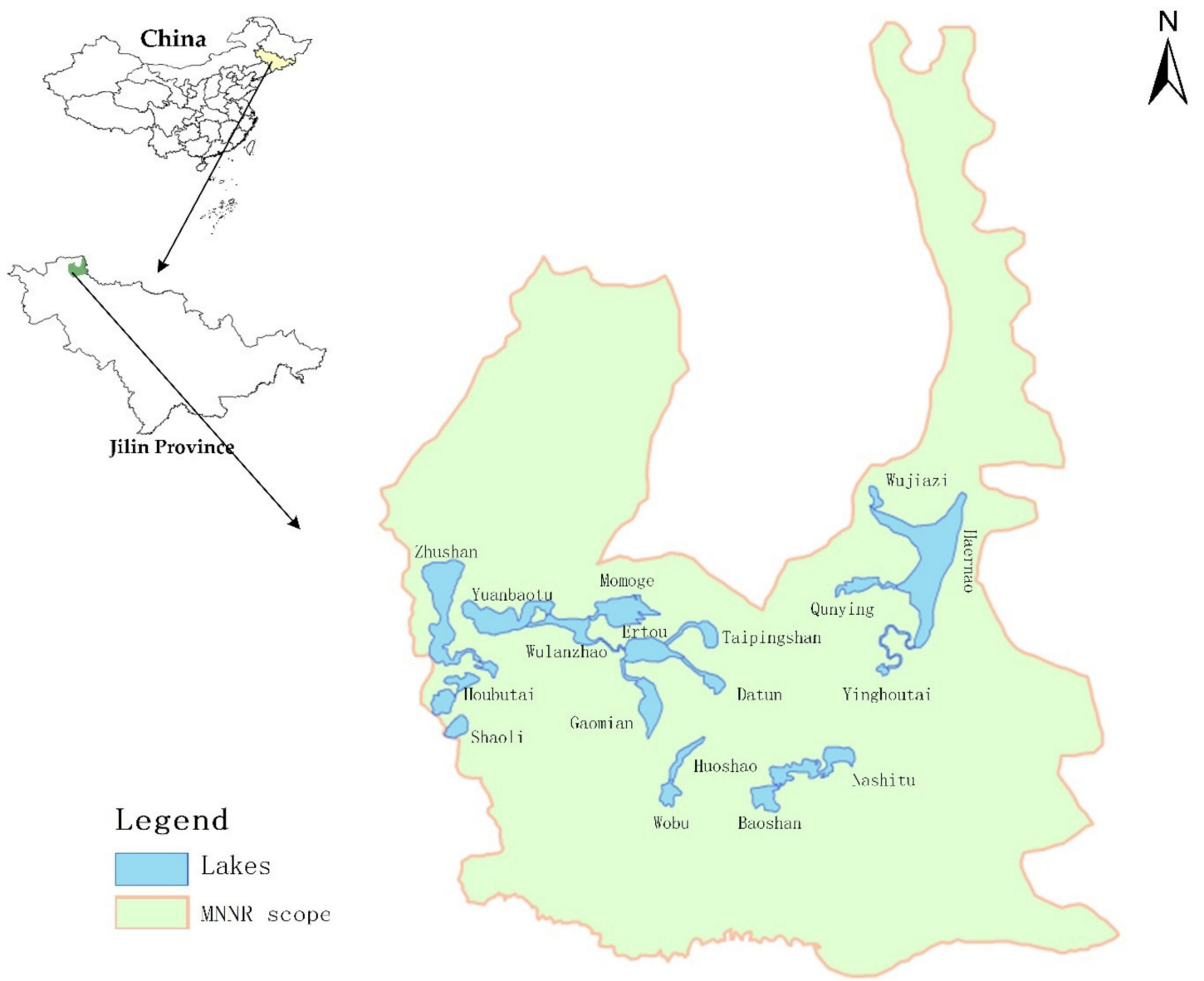

Figure 1. The geographical locations of the study area (MNNR = Momoge National Nature Reserve). 


\section{Modeling}

\subsection{Model Establishment}

The optimal allocation of water resources in the MNNR is aimed at maximizing the restoration and expansion of the habitat area of rare water birds while taking into account the economic and ecological benefits. The study species are first-class protected animals in China and are also the main protected species in the MNNR. Thus, they were selected as the objects of study in this work. According to the living habits of the study species, they can only inhabit and forage in water areas of depth between 0-40 cm [15-18]. Thus, the present work considers the water area with this as a suitable habitat for them. In order to facilitate the calculation, the longitudinal profile of the lakes was assumed to be a regular parabola and the relationship curve of the water level-area-volume of the 18 lakes in the MNNR was simulated and established by referring to the data of the water level-area-volume capacity of the 18 lakes in the recommended project. Based on the relationship curve, the relationship coefficient, $C_{1}$, between the habitat area suitable for the endangered water birds and the water area having a depth greater than $40 \mathrm{~cm}$, was calculated. The proportion of habitat area to total area was observed to decrease with an increase in the water level. Its correlation function was complex and difficult to calculate. Thus, in order to simplify the calculation, a minimum value was taken in this work. A good linear relationship was observed between the total area of the lake and the water volume, and their relationship coefficient, $C_{2}$, was obtained by a linear fitting function. Finally, the relationship coefficient, $C$, between the habitat area and the water volume was calculated based on $C_{1}$ and $C_{2}$.

On the basis of the above-mentioned points, by taking the water supply capacity, the planning scope of the lakes, the ecological water demand of the wetland, the ecological benefits, and the net carbon sink as the constraints, an optimal model of water resource allocation based on the IPTSP method was constructed to maximize the restored habitat area of the rare water birds. The constructed model took the optimal water supply target of each lake as the first stage and the water shortage, caused by the actual water supply not meeting the water supply target, as the second stage. The model comprehensively considered the interval parameters such as the ecological water demand of the wetland and the ecological functional area and the stochastic uncertainty of flood resources in the water resource management system of the MNNR. The model was used to optimize and adjust the initial plan of the ecological water supplement under the scenarios of low, medium, and high flood flow. The random variables were expressed in the form of a probability distribution and the interval parameters were expressed in the form of its upper and lower bounds. The upper bound value of the interval parameter is "+", while the lower bound value is "-". The optimization model built is as follows:

$$
\operatorname{Max} f^{ \pm}=\sum_{i=1}^{18} C_{i}^{ \pm} \cdot Q T_{i}^{ \pm}-\sum_{i=1}^{18} \sum_{h=1}^{3} P_{h} \cdot C_{i}^{ \pm} \cdot Q S_{i h^{\prime}}^{ \pm}
$$

where $f^{ \pm}$is the restored habitat area of rare water birds (in $10^{3}$ ha), $i$ denotes the 18 lakes in the MNNR, and $h$ denotes the flood flow scenario with $h=1,2,3$ representing the low, medium, and high flood flow scenarios, respectively. $P_{h}$ represents the probability of different flow scenarios, $C_{i}^{ \pm}$is the relationship coefficient between the habitat area and the water volume (in $10^{3} \mathrm{ha} / 10^{4} \mathrm{~m}^{3}$ ), $Q T_{i}^{ \pm}$is the optimal water replenishment target of each lake (in $10^{4} \mathrm{~m}^{3}$ ), and $Q S_{i h}^{ \pm}$represents the water shortage under the different flood flow scenarios (in $10^{4} \mathrm{~m}^{3}$ ).

Constraints:

(1) Constraint for minimum water demand:

$$
Q T_{i}^{ \pm}-Q S_{i h}^{ \pm} \geq \sum_{j=1}^{4} A_{i j \min }^{ \pm} \cdot Q R_{i j}^{ \pm}, \forall i, h,
$$


where $j$ denotes the four different ecosystems with $j=1,2,3,4$ representing the fish pond, the crab pond, the reed wetland, and the marsh wetland, respectively, $A_{i j \min }^{ \pm}$is a variable denoting the minimum requirement for different ecological function areas of the lakes (in $10^{3} \mathrm{ha}$ ), and $Q R_{i j}^{ \pm}$is the ecological water demand per unit area of the different ecosystems (in $10^{4} \mathrm{~m}^{3} / 10^{3}$ ha).

(2) Constraints for the water supply capacity:

$$
\begin{gathered}
Q T_{i}^{ \pm}-Q S_{i h}^{ \pm} \leq Q I D_{i h}^{ \pm}+Q N D_{i h}^{ \pm}+Q F D_{i h}^{ \pm}-Q L_{i}^{ \pm}, \forall i, h, \\
\sum_{i=1}^{9} Q F D_{i h}^{ \pm} \leq Q T F_{n h^{\prime}}^{ \pm} n=1, \forall h, \\
\sum_{i=10}^{12} Q F D_{i h}^{ \pm} \leq Q T F_{n h^{\prime}}^{ \pm}, n=2, \forall h, \\
\sum_{i=13}^{16} Q F D_{i h}^{ \pm} \leq Q T F_{n h^{\prime}}^{ \pm} n=3, \forall h, \\
\sum_{i=17}^{18} Q F D_{i h}^{ \pm} \leq Q T F_{n h^{\prime}}^{ \pm} n=4, \forall h, \\
Q I D_{i h}^{ \pm} \leq Q I_{i}^{ \pm}, \forall i, h, \\
Q N D_{i h}^{ \pm} \leq Q N_{i}^{ \pm}, \forall i, h,
\end{gathered}
$$

where $Q I D_{i h^{\prime}}^{ \pm}, Q N D_{i h^{\prime}}^{ \pm}$and $Q F D_{i h}^{ \pm}$represent the local inflow water, the normal replenishment water, and the flood replenishment water, respectively, corresponding to the flood flow scenarios, $h$, of each lake after optimization (in $10^{4} \mathrm{~m}^{3}$ ), $Q L_{i}^{ \pm}$is the loss of water transmission (in $10^{4} \mathrm{~m}^{3}$ ), and $n$ denotes the four water intakes in the MNNR with $n=1,2,3,4$ representing BIA, ZPS, SIG, and HPS, respectively. QTF $F_{n h}^{ \pm}$is the total amount of available flood resources of intakes, $n$, under the different flood flow scenarios (in $10^{4} \mathrm{~m}^{3}$ ). $Q I_{i}^{ \pm}$and $Q N_{i}^{ \pm}$are the available local inflow water and the available normal replenishment water, respectively (in $10^{4} \mathrm{~m}^{3}$ ).

(3) Constraints for the water replenishment order:

$$
\begin{gathered}
\sum_{j=3}^{4} F A_{i j h}^{ \pm} \cdot Q R_{i j}^{ \pm}=\left\{\begin{array}{l}
Q I D_{i h}^{ \pm}+Q N D_{i h}^{ \pm}+Q F D_{i h}^{ \pm}-Q L_{i}^{ \pm}-\sum_{j=1}^{2} F A_{i j h}^{ \pm} \cdot Q R_{i j^{\prime}}^{ \pm} \\
\text {if } \sum_{j=1}^{2} F A_{i j h}^{ \pm} \geq \sum_{j=1}^{2} A_{i j \min }^{ \pm} \\
0, \text { if } \sum_{j=1}^{2} F A_{i j h}^{ \pm} \leq \sum_{j=1}^{2} A_{i j \mathrm{~min}}^{ \pm}
\end{array}, \forall i, h,\right. \\
F A_{i 4 h}^{ \pm} \cdot Q R_{i 4}^{ \pm}=\left\{\begin{array}{l}
\sum_{j=3}^{4} F A_{i j h}^{ \pm} \cdot Q R_{i j}^{ \pm}-F A_{i 3 h}^{ \pm} \cdot Q R_{i 3^{\prime}}^{ \pm}, i f F A_{i 3 h}^{ \pm} \geq A_{i j \mathrm{~min}}^{ \pm} \\
0, \text { if } F A_{i 3 h}^{ \pm} \leq A_{i j \min }^{ \pm}
\end{array}, \forall i, h,\right.
\end{gathered}
$$

where $F A_{i j h}^{ \pm}$denotes the area of the ecosystem $j$ in the lake $i$ under scenario $h$ (in $10^{3}$ ha). The constraint reflects that the priority order of water replenishment in the project is the fish and crab pond, reed wetland, and marsh wetland, respectively.

(4) Constraints for the function zone area:

$$
\sum_{j=1}^{4} F A_{i j h}^{ \pm} \leq T F A_{i}^{ \pm}, \forall i, h,
$$




$$
\begin{gathered}
F A_{i j h}^{ \pm} \leq A_{i j \max ^{\prime}}^{ \pm} \forall i, j, h, \\
\sum_{j=1}^{4} F A_{i j h}^{ \pm} \geq C_{i}^{ \pm} \cdot\left(Q T_{i}^{ \pm}-Q S_{i h}^{ \pm}\right), \forall i, h, \\
\sum_{j=1}^{4} F A_{i j h}^{ \pm} \cdot Q R_{i j}^{ \pm}=Q T_{i}^{ \pm}-Q S_{i h}^{ \pm}, \forall i, h,
\end{gathered}
$$

where TF $A_{i}^{ \pm}$denotes the upper limit of the planning area of the lake $i$ (in $10^{3} \mathrm{ha}$ ), and $A_{i j \max }^{ \pm}$ denotes the upper limit of the area of the ecosystem $j$ in the lake $i$ (in $10^{3}$ ha).

(5) Constraints for the ecological benefit:

$$
\begin{gathered}
\text { OTEB } B_{k h}^{ \pm}=\sum_{i=1}^{18} \sum_{j=1}^{4} F A_{i j h}^{ \pm} \cdot Y_{i j}^{ \pm} \cdot E S V_{j k^{\prime}}^{ \pm}, \forall k, h, \\
O T E B_{k h}^{ \pm} \geq T E B_{k}^{ \pm}, \forall i, h, \\
\sum_{i=1}^{18} \sum_{j=1}^{4} F A_{i j h}^{ \pm} \cdot Y_{i j}^{ \pm} \cdot \sum_{k=1}^{19} E S V_{k h}^{ \pm}-\sum_{i=1}^{18}\left(Q T_{i}^{ \pm}-Q S_{i h}^{ \pm}-Q F D_{i h}^{ \pm}\right) \cdot 0.18 \\
-\sum_{i=1}^{18} Q F D_{i h}^{ \pm} \cdot 0.11 \geq S E B_{m}^{ \pm}, \forall h
\end{gathered}
$$

where $k$ denotes the ecosystem services in the MNNR, OTEB $B_{k h}^{ \pm}$is the benefit of the ecological service $k$ generated by the optimal water replenishment scheme under different flood flow scenarios (in $10^{6} \mathrm{CNY}$ ), $Y_{i j}^{ \pm}$is a variable between 0 and $1, E S V_{j k}^{ \pm}$denotes the ecological benefit per unit area of the ecological service $k$ of ecological function area $j$ (in $10^{6} \mathrm{CNY}$ ), TEB ${ }_{k}^{ \pm}$denotes the benefit of the ecological service $k$ generated by the project recommendation scheme (in $10^{6} \mathrm{CNY}$ ), $S E B_{m}^{ \pm}$denotes the total ecological benefits of the project recommendation scheme (in $10^{6} \mathrm{CNY}$ ), and the normal and flood water replenishment costs are 0.18 and 0.11 (in $\mathrm{CNY} / \mathrm{m}^{3}$ ), respectively. This work only considers the cost of water transmission.

(6) Constraints for the net carbon sink:

$$
\begin{gathered}
\operatorname{OTCS}_{i h}^{ \pm}=\sum_{j=1}^{4} F A_{i j h}^{ \pm} \cdot Y_{i j}^{ \pm} \cdot N C S A_{i j}^{ \pm}, \forall i, h \\
\text { OTCS } \\
\text { ih } \geq T C S_{i}^{ \pm}, \forall i, h,
\end{gathered}
$$

where $O T C S_{i h}^{ \pm}$is the net carbon sink of the ecological function area $j$ of the lake $i$ caused by the optimal scheme (in $\mathrm{t}$ ), $N C S A_{\text {ih }}^{ \pm}$denotes the net carbon sink capacity of the ecological function area $j$ of the lake $i$ (in $t / 10^{3} \mathrm{ha}$ ), TCS $S_{i}^{ \pm}$is the net carbon sink of the ecological function area $j$ of the lake $i$ caused by project recommendation scheme (in $\mathrm{t}$ ).

(7) Other constraints:

$$
\begin{gathered}
Q S_{i h}^{ \pm} \geq 0, \forall i, h, \\
Q F D_{i h}^{ \pm} \geq 0, \forall i, h .
\end{gathered}
$$

Based on the interactive algorithm [48], the IPTSP model was divided into two sub-models that correspond to the lower and upper bounds of the desired objective function value, $f^{+}$and $f^{-}$. By solving the two sub-models, $f_{\text {opt }}^{+}, f_{\text {opt }}^{-}, Q T_{i}, Q S_{\text {ihopt }}^{-}$, and $Q S_{\text {ihopt }}^{+}$were obtained. By combining the solutions, the optimal solutions of the IPTSP model were found to be $f_{\text {opt }}^{ \pm}=\left[f_{\text {opt }}^{-}, f_{\text {opt }}^{+}\right], Q S_{\text {ihopt }}^{ \pm}=\left[Q S_{\text {ihopt }}^{-}, Q S_{\text {ihopt }}^{+}\right]$, 
and the optimal water replenishment schemes were $Q_{i h o p t}^{ \pm}=Q T_{i}-Q S_{i h}^{ \pm}, \forall i, h$. The solution processes of IPTSP model are shown in Supplementary Materials. And the definition of constraints can be seen in Section B in Supplementary Materials.

\subsection{Revision of the Evaluation Index System of the Ecosystem Service Value in the Momoge National Nature} Reserve (MNNR)

Ecosystem services refer to the direct, indirect, tangible, and intangible benefits provided by natural ecosystems and ecosystems modified by humans [55]. There are many classification systems for the ecosystem services, among which the division of ecosystem services proposed by the Millennium Ecosystem Assessment (MA) has been widely accepted and applied. It provides a paradigm and a standard for the value evaluation of the wetland ecosystem services. MA [55] divides the ecosystem service functions into four categories. The first category is the supply services, which include the service of providing ecosystem products such as food for humans. The second category is the regulation services which include the regulation of climate. The third category is the support services, which include functions such as providing habitats. The fourth category is the cultural services, which include educational value.

The project involved in the recommended scheme is an ecological water conservancy project primarily developed for the restoration and protection of wetlands. The project pays attention to not only the socio-economic and environmental benefits, but also the ecological benefits [56]. Therefore, based on the evaluation index system built by Cai et al., [56] and the classification system of MA, an evaluation index system of the ecosystem service of the MNNR, which comprehensively considered the socio-economic, environmental, and ecological benefits, was appropriately revised [57,58]. The revised index system includes four first-level indicators such as supply service, 14 s-level indicators such as food production, and 19 third-level indicators such as oxygen release. Based on the evaluation index system, the ecological service value per unit area of the different ecological function areas was calculated. In order to take the inflation into account, it was necessary to discount the value of the ecological services per unit area to 2017 by referring to the changes in the average output value of three kinds of grains in China, consumer price index, the producer price index, and the price index of investment in fixed assets from 2005-2017. The calculation results are shown in Table 1. The evaluation method of the third-class indices is provided in Supplementary Materials. 
Table 1. Revision system of ecosystem service value evaluation index in the Momoge National Nature Reserve (MNNR) $\left(10^{6} \mathrm{CNY} / 10^{3} \mathrm{ha}\right)$.

\begin{tabular}{|c|c|c|c|c|c|c|}
\hline \multirow{2}{*}{ First Class Indices } & \multirow{2}{*}{ Second Class Indices } & \multirow{2}{*}{ Third Class Indices } & \multicolumn{4}{|c|}{ Ecological Service Value } \\
\hline & & & Fish Pond & Crab Pond & Reed Wetland & Marsh Wetland \\
\hline \multirow{5}{*}{ Supply service } & \multirow{2}{*}{ Food production } & Fish & {$[24.00,28.80]$} & {$[0.00,0.00]$} & {$[0.00,0.00]$} & {$[0.00,0.00]$} \\
\hline & & Crab & {$[0.00,0.00]$} & {$[36.00,43.20]$} & {$[0.00,0.00]$} & {$[0.00,0.00]$} \\
\hline & \multirow{2}{*}{ Raw material production } & Reed & {$[0.00,0.00]$} & {$[0.00,0.00]$} & {$[3.00,3.60]$} & {$[0.00,0.00]$} \\
\hline & & Scirpi & {$[0.00,0.00]$} & {$[0.00,0.00]$} & {$[0.00,0.00]$} & {$[0.16,0.19]$} \\
\hline & Water supply & Water supply & {$[12.80,15.35]$} & {$[12.80,15.35]$} & {$[0.00,0.00]$} & {$[0.00,0.00]$} \\
\hline \multirow{4}{*}{ Regulating services } & Carbon sequestration & Carbon sequestration & {$[0.00,0.00]$} & {$[0.00,0.00]$} & {$[0.69,0.83]$} & {$[0.11,0.13]$} \\
\hline & Atmosphere adjustment & Oxygen release & {$[0.00,0.00]$} & {$[0.00,0.00]$} & {$[6.387 .65]$} & {$[0.96,1.15]$} \\
\hline & Flood regulation & Flood regulation & {$[30.80,36.95]$} & {$[30.80,36.95]$} & {$[4.53,5.44]$} & {$[4.53,5.44]$} \\
\hline & Microclimate adjustment & Cooling and humidification & {$[1.80,2.16]$} & {$[1.80,2.16]$} & {$[11.88,14.26]$} & {$[11.88,14.26]$} \\
\hline \multirow{6}{*}{ Support services } & \multirow{2}{*}{ Degradation pollution } & Plant adsorption & {$[0.00,0.00]$} & {$[0.00,0.00]$} & {$[12.63,15.16]$} & {$[12.63,15.16]$} \\
\hline & & Assimilative capacity & {$[0.00,0.00]$} & {$[0.00,0.00]$} & {$[18.29,21.94]$} & {$[18.29,21.94]$} \\
\hline & \multirow{2}{*}{ Biodiversity maintenance } & Biological habitat & {$[2.34,2.68]$} & {$[2.34,2.68]$} & {$[2.34,2.68]$} & {$[2.34,2.68]$} \\
\hline & & Rare water bird protection & {$[15.53,18.63]$} & {$[15.53,18.63]$} & {$[15.53,18.63]$} & {$[15.53,18.63]$} \\
\hline & Soil conservation & Soil conservation & {$[3.77,4.52]$} & {$[3.77,4.52]$} & {$[9.35,11.21]$} & {$[9.35,11.21]$} \\
\hline & Nutrient cycle & Nutrient cycle & {$[0.28,0.34]$} & {$[0.28,0.34]$} & {$[0.74,0.88]$} & {$[0.74,0.88]$} \\
\hline \multirow{4}{*}{ Cultural Services } & Scientific culture & Scientific culture & {$[0.47,0.56]$} & {$[0.47,0.56]$} & {$[0.47,0.56]$} & {$[0.47,0.56]$} \\
\hline & Leisure tourism & Leisure tourism & {$[3.35,4.01]$} & {$[3.35,4.01]$} & {$[3.35,4.01]$} & {$[3.35,4.01]$} \\
\hline & \multirow{2}{*}{ Aesthetic landscape } & Urban Landscape & {$[1.83,2.20]$} & {$[1.83,2.20]$} & {$[1.83,2.20]$} & {$[1.83,2.20]$} \\
\hline & & Natural landscape & {$[0.74,0.88]$} & {$[0.74,0.88]$} & {$[0.74,0.88]$} & {$[0.74,0.88]$} \\
\hline
\end{tabular}

Note: The two numbers, a and b, within each bracket, represent the lower and upper bounds of the ecosystem service value. 


\subsection{Parameters Descriptions}

In this work, 18 lakes in the MNNR were selected as the study area, and the IPTSP model was solved mainly based on the basic data related to the ecological benefits and other constraints in the project recommendation scheme. Among them, the flood resource is stochastically uncertain and was divided into low, medium, and high flow levels, among which the flood resource of the project recommended scheme corresponds to a medium flow level. On the basis of the water resource sequence of the Nenjiang River in the "Jilin Province Water Resources" from 1956 to 2010, Monte Carlo simulations using the Oracle Crystal Ball (Oracle, Redwood Shores, CA, USA) software were carried out to obtain the probability distribution of the water resources and the results of the calculation are shown in Figure 2. From the figure, it can be seen that the probabilities of the low, medium, and high flood flow levels in the predicted year were $0.50,0.38$, and 0.12 , respectively. The available flood resources of the four water intakes in the study area under the three flood flow scenarios are listed in Table 2. The ecological function planning areas, ecological water demand, and net carbon sink capacity per unit area are shown in Table 3. The relationship coefficient between the habitat area and water volume in shown in Table 4.

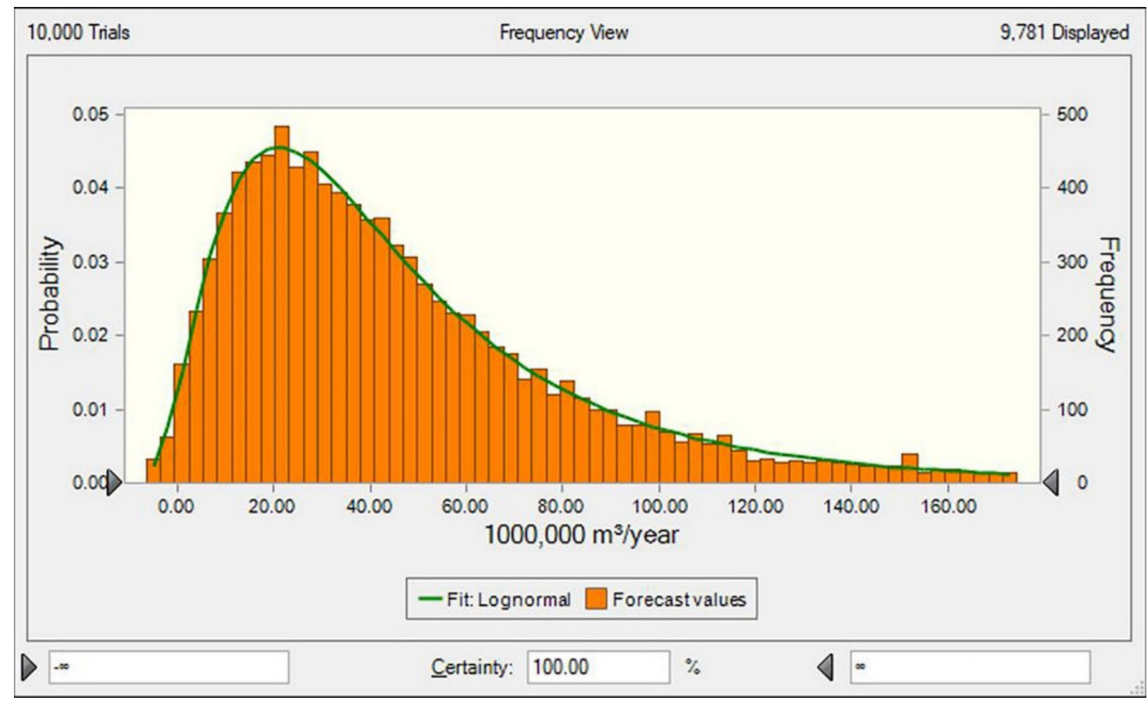

Figure 2. Probability distribution of the water resources in the Nenjiang River.

Table 2. Available water resources of 4 intakes under different scenarios (in $10^{4} \mathrm{~m}^{3} /$ year).

\begin{tabular}{ccccc}
\hline \multirow{2}{*}{ Intakes } & \multirow{2}{*}{ Normal and Local Water } & \multicolumn{3}{c}{ Flood } \\
\cline { 3 - 5 } & & $\mathbf{h}=\mathbf{1} \mathbf{( 0 . 5 0 )}$ & $\mathbf{h}=\mathbf{2}(\mathbf{0 . 3 8})$ & $\mathbf{h}=\mathbf{3} \mathbf{( 0 . 1 2 )}$ \\
\hline BIA & {$[6993.40,9163.90]$} & {$[2158.38,2413.19]$} & {$[2697.98,3447.41]$} & {$[3372.47,4136.90]$} \\
ZPS & {$[3470.05,4491.60]$} & {$[1450.66,1621.91]$} & {$[1813.32,2317.02]$} & {$[2266.65,2780.42]$} \\
SIG & {$[2524.1,3190.8]$} & {$[1653.84,1849.09]$} & {$[2067.30,2641.55]$} & {$[2584.13,3169.86]$} \\
HPS & {$[375.65,489.9]$} & {$[207.36,231.84]$} & {$[259.20,331.20]$} & {$[324.00,397.44]$} \\
\hline
\end{tabular}

Note: $\mathrm{h}=1,2,3$ represent low, medium and high flood flow scenarios; BIA = third branch channel of the Baishatan irrigation area; $\mathrm{ZPS}=$ Zhushan pumping station; $\mathrm{SIG}=$ Shijiangfang intake gate; HPS = Haernao pumping station . 
Table 3. Ecological function planning areas, ecological water demand, and net carbon sink capacity per unit area.

\begin{tabular}{|c|c|c|c|c|c|c|}
\hline & Intakes & Lakes & Fish Pond & Crab Pond & Reed Wetland & Marsh Wetland \\
\hline \multirow{18}{*}{ 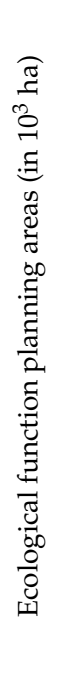 } & \multirow{9}{*}{ BIA } & Yuanbaotu Lake & {$[0.00,0.00]$} & {$[0.40,0.72]$} & {$[0.45,0.81]$} & {$[0.86,1.57]$} \\
\hline & & Wulanzhao Lake & {$[0.00,0.00]$} & {$[0.19,0.40]$} & {$[0.22,0.46]$} & {$[0.42,0.88]$} \\
\hline & & Momoge Lake & {$[0.00,0.00]$} & {$[0.36,0.66]$} & {$[0.41,0.75]$} & {$[0.80,1.45]$} \\
\hline & & Etou Lake & {$[0.00,0.00]$} & {$[0.42,0.88]$} & {$[0.48,1.00]$} & {$[0.92,1.92]$} \\
\hline & & Taipingshan Lake & {$[0.00,0.00]$} & {$[0.14,0.25]$} & {$[0.16,0.29]$} & {$[0.31,0.55]$} \\
\hline & & Datun Lake & {$[0.00,0.00]$} & {$[0.12,0.28]$} & {$[0.14,0.32]$} & {$[0.27,0.61]$} \\
\hline & & Gaomian Lake & {$[0.00,0.00]$} & {$[0.42,0.76]$} & {$[0.47,0.86]$} & {$[0.92,1.66]$} \\
\hline & & Huoshao Lake & {$[0.00,0.00]$} & {$[0.05,0.12]$} & {$[0.06,0.15]$} & {$[0.11,0.27]$} \\
\hline & & Wobu Lake & {$[0.00,0.00]$} & {$[0.10,0.18]$} & {$[0.11,0.21]$} & {$[0.22,0.41]$} \\
\hline & \multirow{3}{*}{ ZPS } & Zhushan Lake & {$[0.00,0.00]$} & {$[0.63,1.24]$} & {$[0.95,1.88]$} & {$[2.72,5.39]$} \\
\hline & & Houbutai Lake & {$[0.00,0.00]$} & {$[0.33,0.48]$} & {$[0.26,0.38]$} & {$[1.50,2.18]$} \\
\hline & & Shaoli Lake & {$[0.00,0.00]$} & {$[0.15,0.26]$} & {$[0.11,0.21]$} & {$[0.66,1.20]$} \\
\hline & \multirow{4}{*}{ SIG } & Haernao Lake & {$[2.17,3.94]$} & {$[0.00,0.00]$} & {$[0.88,1.60]$} & {$[1.47,2.68]$} \\
\hline & & Wujiazi Lake & {$[0.00,0.00]$} & {$[0.07,0.19]$} & {$[0.02,0.05]$} & {$[0.07,0.17]$} \\
\hline & & Qunyin Lake & {$[0.00,0.00]$} & {$[0.46,0.98]$} & {$[0.02,0.04]$} & {$[0.05,0.10]$} \\
\hline & & Yinhoutai Lake & {$[0.00,0.00]$} & {$[0.07,1.80]$} & {$[0.00,0.00]$} & {$[0.02,0.05]$} \\
\hline & \multirow[b]{2}{*}{ HPS } & Nashi Lake & {$[0.00,0.00]$} & {$[0.43,0.62]$} & {$[0.12,0.17]$} & {$[0.01,0.02]$} \\
\hline & & Baoshan Lake & {$[0.00,0.00]$} & {$[0.12,0.30]$} & {$[0.10,0.24]$} & {$[0.02,0.05]$} \\
\hline \multicolumn{3}{|c|}{$\begin{array}{l}\text { Ecological water demand per unit area } \\
\text { (in } 10^{4} \mathrm{~m}^{3} / 10^{3} \mathrm{ha} \text { ) }\end{array}$} & {$[653,718]$} & {$[653,718]$} & {$[698,767]$} & {$[480,528]$} \\
\hline \multicolumn{3}{|c|}{$\begin{array}{l}\text { Net carbon sink capacity per unit area } \\
\text { (in } \mathrm{t} / 10^{3} \mathrm{ha} \text { ) }\end{array}$} & {$[0,0]$} & {$[0,0]$} & {$[3713,4950]$} & {$[387,517]$} \\
\hline
\end{tabular}

Note: BIA = third branch channel of the Baishatan irrigation area; ZPS = Zhushan pumping station; SIG = Shijiangfang intake gate; HPS = Haernao pumping station .

Table 4. Relationship coefficient between the habitat area and water volume (in ha/ $10^{4} \mathrm{~m}^{3}$ ).

\begin{tabular}{cccc}
\hline Intakes & Lakes & Sequences & Relationship Coefficient \\
\hline \multirow{4}{*}{ BIA } & Yuanbaotu Lake & $\mathrm{i}=1$ & {$[0.64,0.74]$} \\
& Wulanzhao Lake & $\mathrm{i}=2$ & {$[1.47,1.69]$} \\
& Momoge Lake & $\mathrm{i}=3$ & {$[0.20,0.23]$} \\
& Etou Lake & $\mathrm{i}=4$ & {$[1.41,1.62]$} \\
& Taipingshan Lake & $\mathrm{i}=5$ & {$[0.08,0.09]$} \\
& Datun Lake & $\mathrm{i}=6$ & {$[1.63,1.88]$} \\
& Gaomian Lake & $\mathrm{i}=7$ & {$[0.43,0.50]$} \\
& Huoshao Lake & $\mathrm{i}=8$ & {$[1.30,1.49]$} \\
& Wobu Lake & $\mathrm{i}=9$ & {$[1.17,1.35]$} \\
\hline \multirow{3}{*}{ ZPS } & Zhushan Lake & $\mathrm{i}=10$ & {$[1.21,1.39]$} \\
& Houbutai Lake & $\mathrm{i}=11$ & {$[0.31,0.35]$} \\
& Shaoli Lake & $\mathrm{i}=12$ & {$[0.43,0.49]$} \\
\hline \multirow{3}{*}{ SIG } & Haernao Lake & $\mathrm{i}=13$ & {$[0.11,0.13]$} \\
& Wujiazi Lake & $\mathrm{i}=14$ & {$[0.56,0.21]$} \\
& Qunyin Lake & $\mathrm{i}=15$ & {$[0.27,0.31]$} \\
\hline \multirow{2}{*}{ HPS } & Yinhoutai Lake & $\mathrm{i}=16$ & {$[0.70,0.80]$} \\
& Nashi Lake & $\mathrm{i}=17$ & {$[0.30,0.34]$} \\
\hline
\end{tabular}

Note: BIA = third branch channel of the Baishatan irrigation area; ZPS = Zhushan pumping station; SIG = Shijiangfang intake gate; HPS = Haernao pumping station . 


\section{Results, Analysis, and Discussion}

4.1. Adjustment of Allocation Scheme of the Water Resources in the Momoge National Nature Reserve (MNNR) through the Interval-Parameter Two-Stage Stochastic Programming (IPTSP) Model

The loss of wetlands in natural reserves is the most important factor leading to a global decline in many species of water birds and poses a serious threat to the health and population integrity of the water birds [59]. Ecological water replenishment is one of the most efficient and direct ways to restore wetland functions [31,32], and this method is also conducive to the restoration and expansion of the habitat area of rare water birds. In order to recover the maximum habitat area of rare and endangered water birds, an optimal allocation model of water resources in the MNNR was established by using the IPTSP method. The Lingo11.0 tool [39] was used for solving the model and the optimal water supply targets of 18 lakes, and the water replenishment schemes under different flood flow scenarios were obtained, as shown in Table 5.

Table 5. Actual optimal water supply of each intake in the Momoge National Nature Reserve (MNNR) of the Jilin Province under different flood flow scenarios (in $10^{4} \mathrm{~m}^{3} /$ year).

\begin{tabular}{ccccc}
\hline \multirow{2}{*}{ Intakes } & $\begin{array}{c}\text { Optimal Water } \\
\text { Supply Target }\end{array}$ & \multicolumn{3}{c}{ Optimal Actual Water Supply } \\
\cline { 3 - 5 } & & Low Flow Level & Medium Flow Level & High Flow Level \\
\hline BIA & 11859.40 & {$[9151.78,11577.09]$} & {$[9691.38,11859.40]$} & {$[10365.87,11859.40]$} \\
ZPS & 7272.02 & {$[4920.71,6113.51]$} & {$[5283.37,6808.62]$} & {$[5736.70,7272.02]$} \\
SIG & 6360.66 & {$[4177.94,5039.89]$} & {$[4591.40,5832.35]$} & {$[5108.23,6360.66]$} \\
HPS & 901.14 & {$[583.01,721.74]$} & {$[634.85,821.10]$} & {$[699.65,887.34]$} \\
\hline
\end{tabular}

Note: BIA = third branch channel of the Baishatan irrigation area; ZPS = Zhushan pumping station; SIG = Shijiangfang intake gate; HPS = Haernao pumping station .

It can be seen from Table 5 that the optimal water supply target of each water intake is the same in the different flood flow scenarios, and on the whole, the targets could not be fully satisfied for any of the three flow scenarios. Among them, the water shortage corresponding to the low flood flow scenario was large, with values of [2941.00,7559.79] $\times 10^{4} \mathrm{~m}^{3}$, while that corresponding to the middle flow scenario was $[1071.75,6192.23] \times 10^{4} \mathrm{~m}^{3}$. The smallest water shortage occurred in the high flow scenario, with values of $[13.80,4482.78] \times 10^{4} \mathrm{~m}^{3}$. From these results, it is clear that with the increase in the inflow, the water shortage of each intake decreases gradually, and the optimal water supply in the MNNR continuously increases. At the same time, these results also indicate that the supply from the water resources in the MNNR is less than the demand, and the MNNR is in a state of water shortage. This is mainly because even though the water supply scheme of the project can alleviate the water shortage of the MNNR, the water supply for the MNNR is still limited [60]. It can be seen from Table 5 that the upper bound value of water supply of the ZPS and SIG were just enough to meet the water supply target under high flood flow scenario, while the upper bound value of the BIA met its water supply target under middle and high flood flow scenarios and there was even surplus water supply. In the case of the medium flood flow scenario, the water supply of the BIA was $[9691.38,12611.31] \times 10^{4} \mathrm{~m}^{3}$, and the upper bound value was $751.91 \times 10^{4} \mathrm{~m}^{3}$ larger than the water supply target. In the case of the high flood flow scenario, the water supply of the BIA was [10365.87,13300.80] $\times 10^{4} \mathrm{~m}^{3}$ and its upper bound value still had a surplus of $1441.39 \times 10^{4} \mathrm{~m}^{3}$. Although the water supply target was not met by the lower bound value, it is still only $12.6 \%$ less. This indicates that the water supply target of the BIA could be satisfactorily met. However, the water supply target of HPS was not met under any of the three flood flow scenarios. Therefore, the decision-making department can divert the remaining water from the BIA to ZPS and SIG under medium flood flow scenario and redirect the remaining water to the HPS under the high flood flow scenario, so as to reduce the water shortage and effectively utilize the limited water resources. 
Figure 3 shows the optimal water supply target of each lake in the MNNR under different flood flow scenarios, corresponding to the initial allocation plan, and the water supply reduction required in the second stage since the optimal water supply target could not be met in the initial plan. As can be seen from the figure, the optimal water supply target for each lake under the different flood flow scenarios was unchanged, with a total volume of $26393.22 \times 10^{4} \mathrm{~m}^{3}$, an increase of $33.68 \%$ with respect to the recommended scheme. The actual optimal water supply is determined by the difference between the optimal water supply target and the water shortage [39]. Due to the different inflow under different scenarios, i.e., high flow level $>$ middle flow level $>$ low flow level, the water shortage of each lake under the different flood flow scenarios was also different. Figure 3 shows that the optimal water supply targets of lakes $2,4,6,8$, and 9 of the BIA were fully met under all three flow scenarios. This indicates that the BIA gave priority to the water replenishment of these five lakes. The two reasons for this observation are (1) lakes 2, 4, 6, 8, and 9 have the five largest habitat area-water volume relationship coefficients among the nine lakes, and a larger habitat area can be gained with the same amount of water replenishment in these lakes; (2) the total water supply target of lakes 2, 4, 6, 8, and 9 was $4691.03 \times 10^{4} \mathrm{~m}^{3}$, accounting for only [40.5\%, 51.3\%] of the actual water supply under the low flood flow scenario, which was easy to meet. In order to maximize the restored habitat area, the model gives priority to the water replenishment of these five lakes. Under the three flood flow scenarios, the water shortage of lake 7 was the largest, which was, respectively [0, 1011.24], [0, 1011.24], and $[0,405.08] \times 10^{4} \mathrm{~m}^{3}$. However, it can be seen from Figure 3 that the water replenishment order of lake 7 was superior to that of lake 3 . From the results of the analysis, it can be seen that the model had to fulfill the minimum water demand of lake 3 to maintain its ecosystem function and then supply water to lake 7 . In addition, the water supply target of lake 7 was too large to be met. This indicates that the relationship coefficient and the water supply target are two important factors affecting the water replenishment sequence of lakes, among which the relationship coefficient is the leading factor. In order to maximize the restored habitat area of rare water birds, the model mainly sorts a water replenishment sequence of the lakes based on the relationship coefficient. For ZPS, it can be seen from Figure $3 \mathrm{a}$ that the water replenishment order of lake 11 was superior to that of lake 12, while from Figure $3 b$, the water replenishment order of lake 10 was superior to that of lakes 11 and 12 . The priority order of water replenishment for the four lakes of the SIG was lake $15>16>14>13$. For the HPS, lake 17 had priority of water replenishment over lake 18. The sequence of water replenishment of lakes in each intake is the same as that of the corresponding relationship coefficient, which is consistent with the above conclusions.

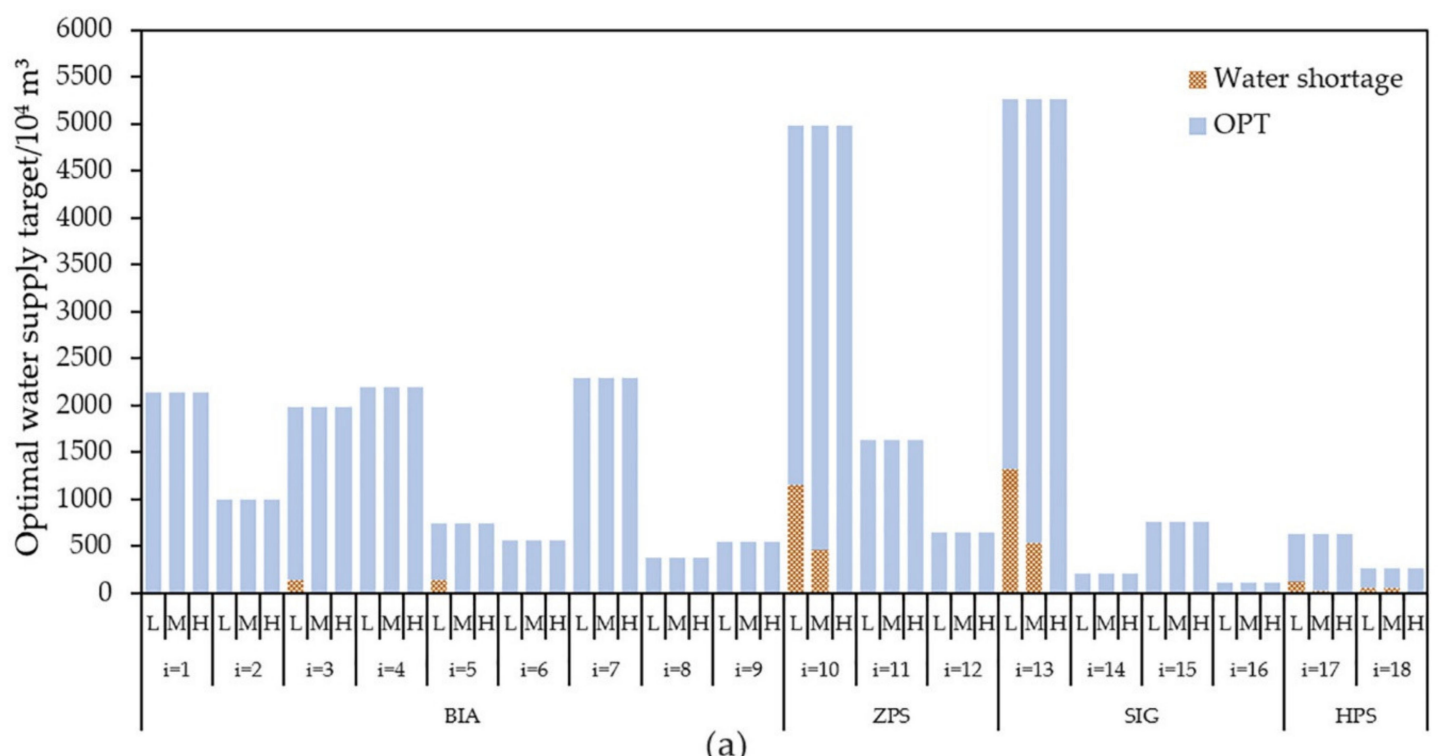

Figure 3. Cont. 


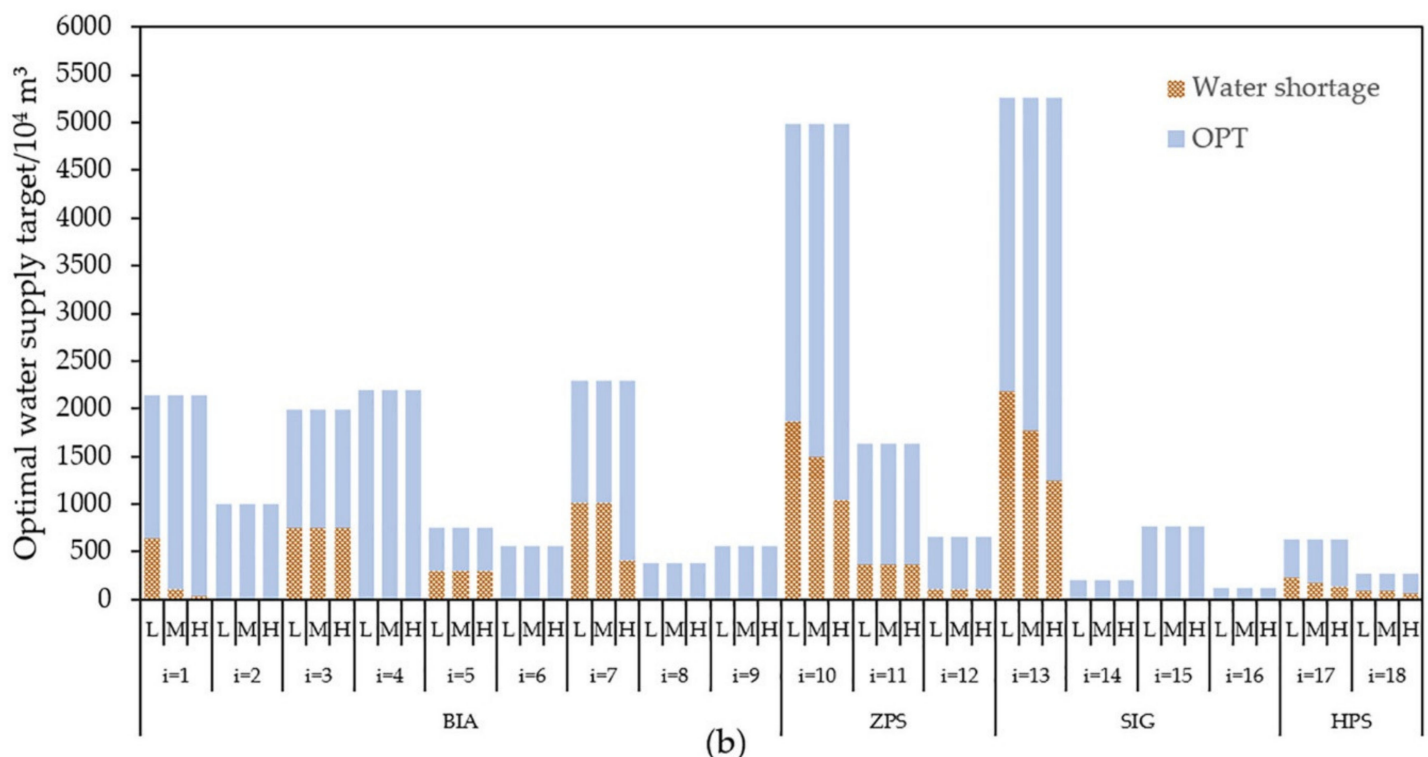

Figure 3. Water supply of each lake in the Momoge National Nature Reserve (MNNR) under different flood flow scenarios. Panel (a) shows the upper bound, while panel (b) shows the lower bound. L, M, and $\mathrm{H}$ denote low, middle, and high flow scenarios, respectively. The blue part represents the optimal actual water supply, while the red part represents a water shortage.

4.2. Calculation of the Habitat Area for Rare Water Birds before and after the Interval-Parameter Two-Stage Stochastic Programming (IPTSP) Model Employed in the Momoge National Nature Reserve (MNNR)

Based on the water level-area-volume relationship curve, the relationship coefficient between the habitat area of endangered water birds and the water volume in each lake bubble was obtained. On this basis, the restored habitat area of the endangered water birds in each lake was calculated as per the water replenishment schemes under the three flood flow scenarios. The results are shown in Table 6.

Table 6. Comparison of the habitat areas of rare and endangered water birds restored by different water replenishment schemes (in $10^{3} \mathrm{ha}$ ).

\begin{tabular}{ccccc}
\hline \multirow{2}{*}{ Habitat Area } & \multirow{2}{*}{$\begin{array}{c}\text { Recommended } \\
\text { Scheme }\end{array}$} & Optimization Schemes \\
\cline { 3 - 5 } & 13.36 & {$[13.99,18.59]$} & Medium Flow Level & High Flow Level \\
\hline Total value & 13.36 & & {$[14.85,19.78]$} & {$[15.80,20.53]$} \\
Expectation & & & {$[14.53,19.28]$} & \\
\hline
\end{tabular}

Table 6 lists the total and the expected values of the habitat area of rare water birds restored by the optimal water replenishment scheme under the three flood flow scenarios and the project recommendation scheme in the MNNR. On the whole, the habitat area restored by the recommended scheme and the optimized schemes under low, medium, and high flood flow scenarios accounted for $39.04 \%$, [45.34\%, 47.66\%], [44.82\%, 47.60\%], and [44.58\%, 46.64\%], respectively, of the total restoration wetland area. Xia et al. [5] found that the habitat area of birds was $24-63 \%$ of the natural wetland area, while Cui et al. [25] found that the proportion was $65.30 \%$. The results of this work are consistent with the two previous studies. It can be seen from Table 6 that the habitat area of rare water birds restored by the optimization schemes under the three flood flow scenarios are increased by [4.7\%, 39.1\%], $[11.1 \%, 48.0 \%]$, and $[18.2 \%, 53.6 \%]$, respectively as compared to that due to the recommended scheme. The area increase is the largest under the high flood flow scenario (as shown in Figure 4). Further, the expected value was $[8.8 \%, 44.3 \%]$ larger than the planned value. This shows that the optimized model can effectively increase the restored habitat area of rare water birds. Alminagorta et al. [40] confirmed this by using the optimization model to increase the habitat area of water birds by the 
optimization scheme to twice that of the basic scheme. On the other hand, on comparing the interval value of the restored habitat area by the three optimization schemes, it can be found that the upper bound value improved significantly as compared to the lower bound value, which is also highlighted from a comparison of Figure $4 b$,c. This indicates that the model results have a large decision space for managers to use. In addition, with the increase in the water supplement, the habitat area of rare water birds recovered under the low, medium, and high flood flow scenarios is also seen to increase. As compared to the low flood flow scenario, the habitat area in the case of the medium and high flood flow scenarios increases by $[6.2 \%, 6.4 \%]$, and $[10.4 \%, 13.0 \%]$, respectively. This indicates that the decision-making department can propose more scientific, rational, and effective water replenishment schemes with the help of the optimization model to improve the utilization rate of flood resources [39].

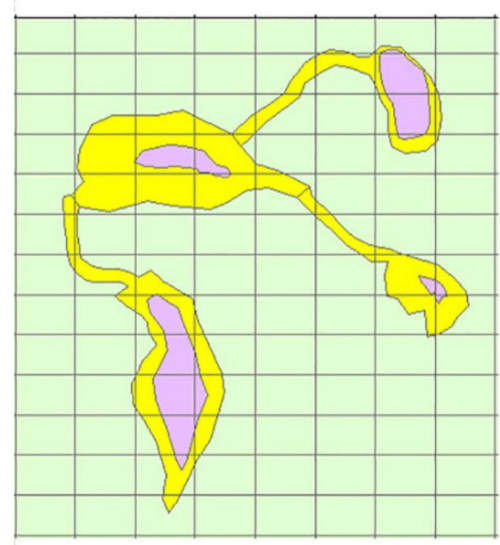

(a)

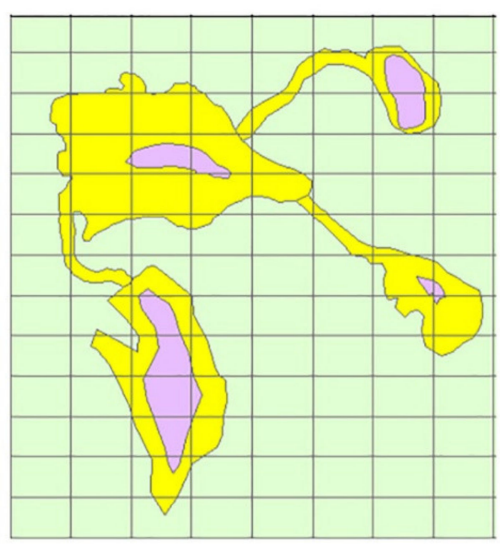

(b)

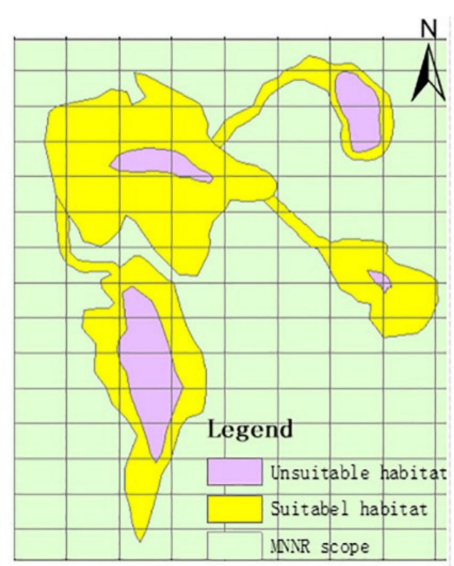

(c)

Figure 4. Schematic diagram of the habitat area restoration of some lakes under different water replenishment schemes. Panel (a) shows the recommended scheme, panels (b) and (c) show the lower bound and upper bounds of the optimal scheme under the high flood flow scenario.

According to the ecological habits of the Siberian crane, oriental stork, and red-crowned crane, they migrate to the MNNR in spring and autumn and stay there for one to two months [61]. According to the project recommendation scheme, Siberian cranes and oriental storks migrate here in autumn with their young ones. Siberian cranes move here between early September to early October and leave between late October to early November. Oriental storks arrive in the middle of September and depart in early November. Red-crowned cranes move here in early October and leave during late October to early November. The water replenishment period of the MNNR is from July to September, and it is completed just at the time of their migration, such that a suitable habitat area for them is restored and expanded. Therefore, a larger number of such suitable habitats and foraging areas, as well as abundant food, are available for them, which increases the carrying capacity of suitable habitat areas in the MNNR for rare water birds. According to Xiao [62], the distribution density of the study species in the MNNR is about $0.76 \mathrm{ha}$ /number. From the calculations done in this work, the total carrying capacity of the MNNR according to the optimization schemes under low, medium, and high flood flow scenarios was $[18.40,24.46] \times 10^{3},[19.54,26.03] \times 10^{3}$, and $[20.79,27.01] \times 10^{3}$ birds, respectively, with an increase of $[0.82,6.88] \times 10^{3},[1.96,8.45] \times 10^{3}$, and $[3.21,9.43] \times 10^{3}$ birds, respectively, as compared to that of the recommended scheme. This result is in line with the estimated result of Xiao [62]. As a result, the survival chances of the study species, as per the optimization schemes, were improved by $[4.7 \%, 39.1 \%],[11.1 \%, 48.0 \%]$, and $[18.2 \%, 53.6 \%]$, respectively, as compared to that predicted by the project recommendation scheme. The increase of the habitat area is conducive to the growth and survival of chicks and a guarantee for their continued southward migration [63]. The mortality during their southward migration can be reduced, thus enabling their recovery and increase in their population, which is of great significance to the safety of the rare water birds [25]. 
Figure 5 shows the relationship between the habitat area of rare water birds restored by the project recommendation scheme and that restored by the optimized water replenishment scheme under the three flood flow scenarios in the 18 lakes of the MNNR. It can be seen from the figure that for the BIA, the restored habitat areas of lakes 2, 4, 6, 8, and 9 all reach a peak and do not change under the three flood flow scenarios. In addition, the restored areas are larger than the restoration achieved by the recommended scheme, with an increase of [50.0\%, 72.5\%], [50.0\%, 72.5\%], [28.3\%, 47.6\%], $[105.4 \%, 136.3 \%]$, and $[57.1 \%, 80.6 \%]$, respectively, for the five lakes. The primary reasons for this are as follows: (1) the water supply targets of these lakes in the optimization schemes were larger than the corresponding targets in the project recommendation scheme; (2) these lakes were given priority for their water replenishment so that the water supply targets of these lakes were met under all three flood flow scenarios. Under the different flood flow scenarios, the variation of the restored habitat area of the lakes corresponding to the BIA fluctuated only by a small amount. This is mainly because the optimal water supply of the BIA was relatively adequate and close to the optimal water supply target. For the ZPS, the restored habitat area of lake 10 increased with the increase in flood flow level, while that of lake 11 and 12 did not change due to being affected by the water replenishment sequence. Further, the total inflow was insufficient, and thus the model chose to supply water to lake 10 as much as possible. In the case of the lakes fed by the SIG and HPS, the restored habitat area of each lake using the optimal scheme under the different flood flow scenarios had little change and also showed little difference from the results achieved by the project recommendation scheme. On comparing the restored habitat areas of each lake, it can be seen that the restored habitat areas of lakes 1, 2, 4, 6, 7, and 10 were the largest. Their total habitat area accounted for more than $51.3 \%$ under different flood flow scenarios. These lakes also had the highest carrying capacity for rare water birds and the highest probability of Siberian cranes and other rare water birds inhabiting here. These results are in line with the actual situation in which a large number of rare water birds such as Siberian cranes can be observed in Yuanbaotu Lake, Wulanzhao Lake, Etou Lake, Zhushang Lake, Datun Lake, and Gaomian Lake $[15,18]$.

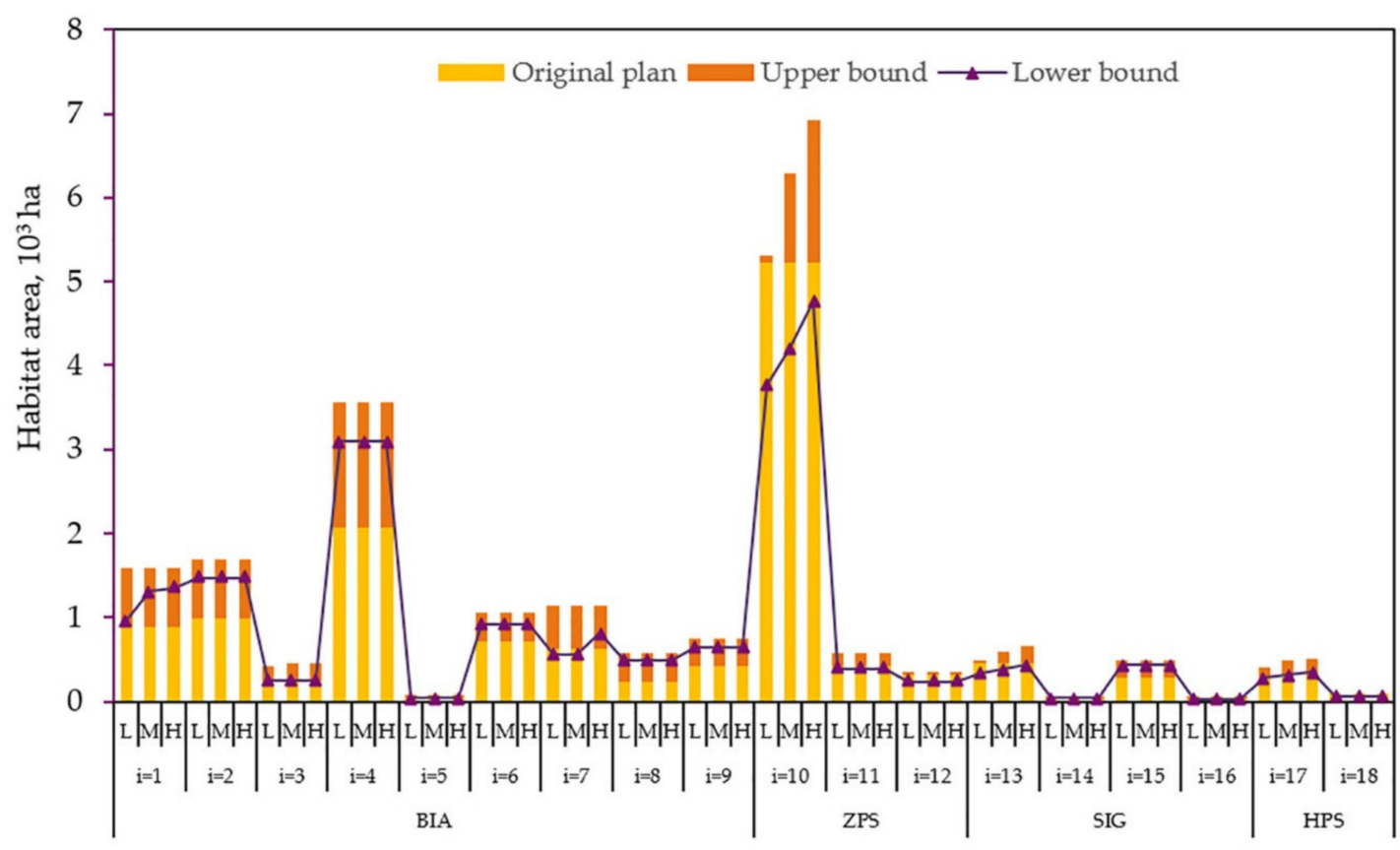

Figure 5. Restored habitat areas of rare water birds in 18 lakes by the recommended scheme and the optimization scheme under the different flow scenarios of water replenishment. 
4.3. Potential for Improvement of the Reed Wetland, Marsh Wetland, Fish Pond, and Crab Pond in the Momoge National Nature Reserve (MNNR) Using the Interval-Parameter Two-Stage Stochastic Programming (IPTSP) Model

Figure 6 shows the areas of the reed wetland, marsh wetland, fish pond, and crab pond restored by the project recommendation scheme and the optimization schemes under the three flood flow scenarios in the MNNR. On the whole, the total restored wetland area under the three scenarios is seen to increase with the increase of the flow level, with the obtained values of $[-14.3 \%, 19.8 \%],[-8.8 \%, 28.9 \%]$, $[-1.0 \%, 34.5 \%]$ as compared to that of the recommended project. The same law was also reflected in the net carbon sink and ecological benefits.

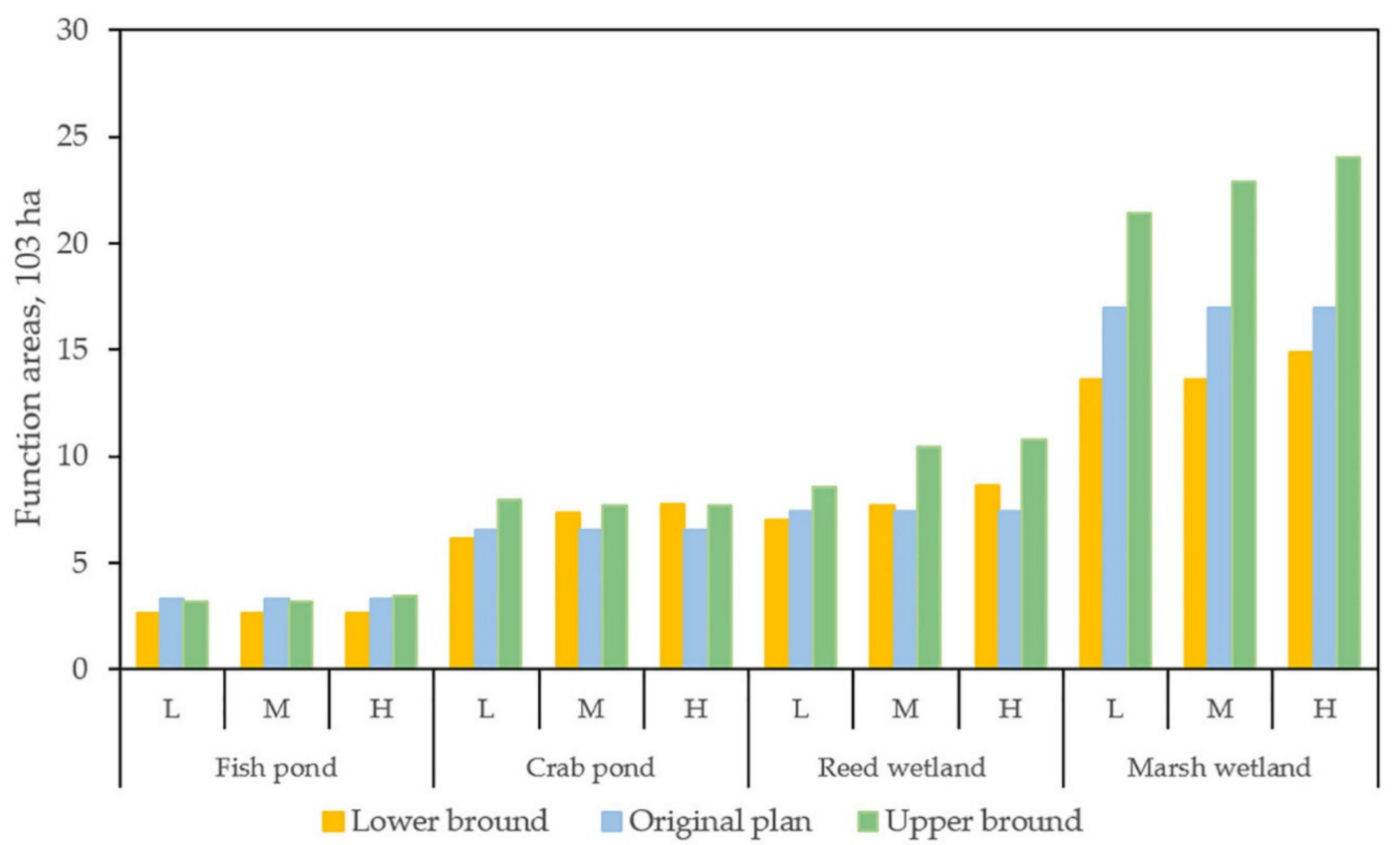

Figure 6. The restored ecological functional areas of the Momoge National Nature Reserve (MNNR) by recommended scheme and optimization schemes under different flow scenarios of water replenishment.

Locally, under the three flood flow scenarios, the restored area of the fish pond was unchanged, and the added value was negative, $[-0.66,-0.14] \times 10^{3}$ ha. This is mainly due to the fact that only Haernao Lake has the function of raising fish. In addition, the actual water supply for Haernao Lake was insufficient, and as a result, the demand for water replenishment was not met. The situation of the crab pond is the same as the fish pond. The restored area of the crab pond using the optimal scheme under the three flood flow scenarios had a minute change. However, all of them were larger than that of the project recommendation scheme. This is because the ecological benefit per unit area of the crab pond is the largest. In addition, the water quantity was insufficient on the whole, and thus, the recoverable area was limited. In order to meet the constraints of the ecological benefits, the model chose to increase the crab pond area used for raising crabs to some extent. As compared to the restored area of the reed wetland under low, medium, and high flood flow conditions, it can be seen that with the increase of the flow level, the restored area also increased by $[-0.45,1.09] \times 10^{3} \mathrm{ha},[0.22,2.99] \times 10^{3} \mathrm{ha}$, and $[1.16,3.37] \times 10^{3}$ ha, respectively. This is because of two main reasons: (1) although the ecological benefit per unit area of the reed wetland is smaller than that of the crab pond, it is larger than that of the marsh wetland. Therefore, the model chose to restore the area of the reed wetland in order to obtain larger ecological benefits. (2) It was not only the economic benefits, but also the environmental benefits that were considered in this work. Reed and marsh wetlands also have the ecological function of carbon sequestration and oxygen release by vegetation as compared to the fish and crab ponds. In addition, the capacity of vegetation in the reed wetland to sequester carbon and release oxygen is ten times that of the marsh wetland due to the larger biomass per unit area of the reed wetland. Therefore, 
the increase in the reed wetland area can meet the constraint of net carbon sink efficiently and achieve higher environmental benefits. However, the reed wetland has the largest water requirement per unit area, and the overall water supply is insufficient, and thus, the increase in the restored area of the reed wetland was small. The same observation is also reflected in the marsh wetland. The restored area of the marsh wetland under the three flood flow scenarios was the largest and the range of change was also the largest with an increase of $[-3.40,4.42] \times 10^{3}$ ha, $[-3.40,5.91] \times 10^{3}$ ha, and $[-2.06,7.08] \times 10^{3}$ ha, respectively. This is mainly because, although the ecological benefits per unit area and the capacity of carbon sequestration and oxygen release of the marsh wetland are small, the water requirement per unit area is the smallest, which is only 0.69 times that of the reed wetland and 0.74 times that of the crab pond. In the case of overall insufficient water supply, a larger quantity of water was chosen to be supplied to the marsh wetland. In this way, not only the economic as well as environmental benefits can be obtained, but the total restoration area of the wetland is also enhanced. This is also one of the important reasons why the area of fish and crab ponds had a little change.

\section{Conclusions}

In this study, based on the interval-parameter two-stage stochastic programming method, an optimal allocation of water resources was constructed to maximize the restored habitat area of the Siberian crane, oriental stork, and red-crowned crane in the MNNR. The constructed model can efficiently deal with the random uncertainty of the flood resources and the interval parameters in the water resources system of the MNNR. Optimal water replenishment schemes for 18 lakes of the MNNR under different flood flow scenarios were obtained, and the restored wetland and habitat areas of rare and endangered water birds under the corresponding scenarios were estimated.

The optimal water supply target of the MNNR was not fully met under the three flood flow scenarios. The water shortage was observed to decrease with the increase in the flood flow level, with the water shortage of $[2941.00,7559.79] \times 10^{4} \mathrm{~m}^{3},[1071.75,6192.23] \times 10^{4} \mathrm{~m}^{3}$, and $[13.80,4482.78] \times 10^{4} \mathrm{~m}^{3}$, respectively. The results indicate that increasing the effective utilization of the flood resources can alleviate the water shortage to some extent. Under the low, medium, and high flood flow scenarios, the habitat area of rare water birds restored by water replenishment was larger than that estimated according to the project recommendation scheme, with an increase of [4.7\%, 39.1\%], [11.1\%, 48.0\%], and $[18.2 \%, 53.6 \%]$, respectively. As a result, the carrying capacity for study species increased by $[0.82,6.88],[1.96,8.45]$, and $[3.21,9.43] \times 10^{3}$ birds in comparison to that estimated according to the restored habitat areas of the recommended scheme, correspondingly. The results show that by using the optimization model, the limited water resources can be effectively used to increase the restored habitat area of study species for higher carrying capacity of them, recover the ecological functioning of the wetlands, and achieve better ecological and environmental benefits under three flow scenarios. The results of this study can provide valuable theoretical support for the administration of nature reserves to restore and increase the habitat areas and population of rare water birds and to manage and plan limited water resources under different scenarios. Moreover, the results of this study can provide decision space for the administrative department to adjust the planning scheme according to the actual situations. The model proposed in this work can also be applied to other areas and other management optimization problems.

In this work, the IPTSP method was used to allocate normal water and flood resources under three flood flow scenarios. However, only the water depth and potential food availability, but not other influencing factors, were considered in the model when defining the suitable habitat for water birds. In addition, the planning scopes of lake and wetland ecosystems by relevant national and local authorities are often fuzzy and uncertain, but the fuzzy uncertainty was not taken into account in the model. Further research is needed to solve the problem of the restoration and protection of habitat area for rare water birds through replenishing water. 
Supplementary Materials: The following are available online at http://www.mdpi.com/2073-4441/12/6/1520/s1, Table S1: Evaluation method of ecosystem service value evaluation index system, Definition, The solution processes of IPTSP model.

Author Contributions: Conceptualization, X.L.; methodology, X.L. and C.M.; software, X.L. and C.M.; validation, W.Z.; formal analysis, X.L. and B.C.; resources, B.C.; data curation, X.L.; writing-original draft preparation, X.L.; writing-review and editing, W.Z.; project administration, W.Z. All authors have read and agreed to the published version of the manuscript.

Funding: This research received no external funding.

Conflicts of Interest: The authors declare no conflict of interest.

\section{References}

1. Aguilera, H.; Moreno, L.; Wesseling, J.G.; Jimenez-Hernández, M.E.; Castano, S. Soil moisture prediction to support management in semiarid wetlands during drying episodes. Catena 2016, 147, 709-724. [CrossRef]

2. Berkowitz, J.F.; Green, L.; VanZomeren, C.M.; White, J.R. Evaluating soil properties and potential nitrate removal in wetlands created using an engineering with nature based dredged material placement technique. Ecol. Eng. 2016, 97, 381-388. [CrossRef]

3. Lavoie, R.; Deslandes, J.; Proulx, F. Assessing the ecological value of wetlands using the macbeth approach in Quebec City. J. Nat. Conserv. 2016, 30, 67-75. [CrossRef]

4. Mitsch, W.J.; Bernal, B.; Nahlik, A.M.; Mande, U.; Zhang, L.; Anderson, C.J.; Jorgensen, S.E.; Brix, H. Wetlands, carbon, and climate change. Landsc. Ecol. 2013, 28, 583-597. [CrossRef]

5. Xia, S.X.; Yu, X.B.; Fan, N. The wintering habitats of migrant birds and their relationship with water level in Poyang Lake, China. Resour. Sci. 2010, 32, 2073-2078.

6. Kanai, Y.; Ueta, M.; Germogenov, N.; Nagendran, M.; Mita, N.; Higuchi, H. Migration routes and important resting areas of Siberian Crane (Grus leucogeranus) that migrate from northeastern Siberia and China revealed by satellite tracking. Biol. Conserv. 2002, 106, 339-346. [CrossRef]

7. Zhang, Y.; Wang, Z.M.; Ren, C.Y.; Yu, H.; Dong, Z.Y.; Lu, C.Y.; Mao, D.H. Change in habitat suitability for waterbirds of the Momoge Reserve of China during 1990-2014. J. Environ. Eng. Landsc. 2017, 25, 367-378. [CrossRef]

8. Isola, C.R.; Colwell, M.A.; Taft, O.W.; Safran, R.J. Interspecific differences in habitat use of shorebirds and waterfowl foraging in managed wetlands of California's San Joaquin Valley. Waterbirds 2000, 23, 196-203.

9. Ma, Z.J.; Cai, Y.T.; Li, B.; Chen, J.K. Managing wetland habitats for waterbirds: An international perspective. Wetlands 2010, 30, 15-27. [CrossRef]

10. Taft, O.W.; Colwell, M.A.; Isola, C.R.; Safran, R.J. Waterbird responses to experimental drawdown: Implications for the multispecies management of wetland mosaics. J. Appl. Ecol. 2002, 39, 987-1001. [CrossRef]

11. Gawlik, D.E. The effects of prey availability on the numerical response of wading birds. Ecol. Monogr. 2002, 72, 329-346. [CrossRef]

12. Shao, M.Q.; Jiang, J.H.; Guo, H.; Zeng, B.B. Abundance, distribution and diversity variations of wintering water birds in Poyang Lake, Jiangxi Province, China. Pak. J. Zool. 2014, 46, 451-462.

13. Zhi, Y.J.; Lu, P.; Dai, N.H.; Shao, M.Q.; Zeng, J.H. Foraging behavior of Siberian Cranes in lotus pond habitats surrounding Poyang Lake. Acta Ecol. Sin. 2019, 39, 4266-4272.

14. Wu, J.D.; Li, F.S.; Brunham, J. Numerical distribution of Siberian cranes and their relation to food and water depth in Sha Hu at Poyang Lake, China. Wetl. Sci. 2013, 11, 305-312.

15. He, C.G.; Song, Y.J.; Lang, H.Q.; Li, H.K.; Sun, X.W. Migratory dynamics of Siberian crane and environmental conditions at its stop-over site. Biodivers. Sci. 2002, 10, 286-290.

16. Zhou, L.Z.; Xu, W.W.; Zhu, S.Y.; Shan, K.; Chen, J.L. Foraging Habitat Use of Oriental Stork (Ciconia boyciana) Recently Breeding in China. Zool. Sci. 2013, 30, 559-564. [CrossRef]

17. Yoon, J.M.; Na, S.H.; Kim, S.K.; Park, S.R. Use of the foraging area by captive bred Oriental storks (Ciconia boyciana) in a closed semi natural paddy field. J. Ecol. Field Biol. 2012, 35, 149-155. [CrossRef] 
18. Jiang, H.X.; Liu, C.Y.; Sun, X.W.; Lu, J.; Zou, C.L.; Hou, Y.Q.; Lu, X.G. Remote sensing reversion of water depths and water Management for the stopover site of Siberian cranes at Momoge, China. Wetlands 2015, 35, 369-379. [CrossRef]

19. Bolduc, F.; Afton, A.D. Relationships between wintering waterbirds and invertebrates, sediments and hydrology of coastal marsh ponds. Waterbirds 2004, 27, 333-341. [CrossRef]

20. Klaassen, R.H.G.; Nolet, B.A.; Bankert, D. Movement of foraging tundra swans explained by spatial pattern in cryptic food densities. Ecology 2006, 87, 2244-2254. [CrossRef]

21. Boettcher, R.; Haig, S.M.; Bridges, W.C. Habitat-related factors affecting the distribution of non-breeding American avocets in Coastal South Carolina. Condor 1995, 97, 68-81. [CrossRef]

22. Liu, B.; Jiang, M.; Tong, S.Z.; Zhang, W.G.; Wu, H.T.; Liu, Y.; Lu, X.G. Differential flooding impacts on echinochloa caudata and Scirpus planiculmis: Implications for weed control in wetlands. Wetlands 2016, 36, 979-984. [CrossRef]

23. Jiang, H.B.; Wen, Y.; Zou, L.F.; Wang, Z.Q.; He, C.G.; Zou, C.L. The effects of a wetland restoration project on the Siberian crane (Grus leucogeranus) population and stopover habitat in Momoge National Nature Reserve, China. Ecol. Eng. 2016, 96, 170-177. [CrossRef]

24. Kong, W.Y.; Zheng, Z.H.; Wu, J.C.; Ning, Y.; Wang, Y.; Han, X.D. Foraging habitat selection of Siberian Crane (Grus leucogeranus) during autumn migration period in the Momoge Nature Reserve. Zool. Res. 2013, 34, 166-173.

25. Cui, Z.; Zhang, G.X.; Zhang, L.; Wu, Y. Eco-hydrological regulations based on requirement of Grus leucogeranus habitat-A case of Baihe Lake in Momoge National Nature Reserve. Wetl. Sci. 2018, 16, 510-516.

26. Na, X.D.; Zang, S.Y.; Zhang, Y.H.; Li, W.L. Assessing breeding habitat suitability for the endangered red-crowned crane (Grus japonensis) based on multi-source remote sensing data. Wetlands 2015, 35, 955-967. [CrossRef]

27. Na, X.D.; Zhou, H.T.; Zang, S.Y.; Wu, C.S.; Li, W.L.; Li, M. Maximum Entropy modeling for habitat suitability assessment of Red-crowned crane. Ecol. Indic. 2018, 91, 439-446. [CrossRef]

28. Chen, B.; Cui, P.; Xu, H.G.; Lu, X.G.; Lei, J.C.; Wu, Y.; Shao, M.Q.; Wu, J.; Cao, M.C.; Liu, G.H. Assessing the suitability of habitat for wintering Siberian cranes (Leucogeranus leucogeranus) at different water levels in Poyang lake area, China. Pol. J. Ecol. 2016, 64, 84-97. [CrossRef]

29. Wu, Q.M.; Zou, H.F. Nest-site selection pattern of Grus japonensis in Zhalong nature reserve of northeast China. J. For. Res. 2011, 22, 281-288. [CrossRef]

30. Li, C.L.; Yang, Y.; Wang, Z.; Yang, L.; Zhang, D.M.; Zhou, L.Z. The relationship between seasonal water level fluctuation and habitat availability for wintering waterbirds at Shengjin Lake, China. Bird Conserv. Int. 2019, 29, 100-114. [CrossRef]

31. Ding, Y.; Liu, H.F.; Yang, W.; Xing, L.M.; Tu, G.Q.; Ru, Z.M.; Xu, Z.H. The assessment of ecological water replenishment scheme based on the two-dimensional lattice-Boltzmann water age theory. J. Hydro-Environ. Res. 2019, 25, 25-34. [CrossRef]

32. Yang, W. A multi-objective optimization approach to allocate environmental flows to the artificially restored wetlands of China's Yellow River Delta. Ecol. Modell. 2011, 222, 261-267. [CrossRef]

33. McCarthy, M.J.; Radabaugh, K.R.; Moyer, R.P.; Muller-Karger, F.E. Enabling efficient, large-scale high-spatial resolution wetland mapping using satellites. Remote Sens. Environ. 2018, 208, 189-201. [CrossRef]

34. Cai, B.F.; Zhang, Y.; Wang, X.E.; Li, Y. An optimization model for a wetland restoration project under uncertainty. Int. J. Environ. Res. Public Health 2018, 15, 2795. [CrossRef]

35. Raum, S. Reasons for adoption and advocacy of the ecosystem services concept in UK forestry. Ecol. Econ. 2018, 143, 47-54. [CrossRef]

36. Turner, R.K.; Adger, W.N.; Brouwer, R. Ecosystem services value, research needs, and policy relevance: A commentary. Ecol. Econ. 1998, 25, 61-65. [CrossRef]

37. Turner, K.G.; Anderson, S.; Gonzales-Chang, M.; Costanza, R.; Courville, S.; Dalgaard, T.; Dominati, E.; Kubiszewski, I.; Ogilvy, S.; Porfirio, L.; et al. A review of methods, data, and models to assess changes in the value of ecosystem services from land degradation and restoration. Ecol. Model. 2016, 319, 190-207. [CrossRef] 
38. Rey Benayas, J.M.; Newton, A.C.; Diaz, A.; Bullock, J.M. Enhancement of biodiversity and ecosystem services by ecological restoration: A meta-analysis. Science 2009, 325, 1121-1124. [CrossRef]

39. Qiu, Y.; Liu, Y.; Liu, Y.; Chen, Y.Z.; Li, Y. An interval two-stage stochastic programming model for flood resources allocation under ecological benefits as a constraint combined with ecological compensation concept. Int. J. Environ. Res. Public Health 2019, 16, 1033. [CrossRef] [PubMed]

40. Alminagorta, O.; Rosenberg, D.E.; Kettenring, K.M. Systems modeling to improve the hydro-ecological performance of diked wetlands. Water Resour. Res. 2016, 52, 7070-7085. [CrossRef]

41. Huang, G.H. A hybrid inexact-stochastic water management model. Eur. J. Oper. Res. 1998, 107, $137-158$. [CrossRef]

42. Rode, M.; Suhr, U. Uncertainties in selected river water quality data. Hydrol. Earth Syst. Sci. 2007, 11, 863-874. [CrossRef]

43. Li, X.M.; Huo, Z.L.; Xu, B. Optimal allocation method of irrigation water from river and lake by considering the field water cycle process. Water 2017, 9, 991. [CrossRef]

44. Yang, G.Q.; Guo, P.; Li, M.; Fang, S.Q.; Zhang, L.D. An improved solving approach for interval-parameter programming and application to an optimal allocation of irrigation water problem. Water Resour. Manag. 2016, 30, 701-729. [CrossRef]

45. Cai, Y.P.; Lin, X.; Yue, W.C.; Zhang, P.P. Inexact fuzzy chance-constrained programming for community-scale urban stormwater management. J. Clean. Prod. 2018, 182, 937-945. [CrossRef]

46. Maqsood, I.; Huang, G.H.; Yeomans, J.S. An interval-parameter fuzzy two-stage stochastic program for water resources management under uncertainty. Eur. J. Oper. Res. 2005, 167, 208-225. [CrossRef]

47. Guo, S.S.; Zhang, F.; Zhang, C.L.; Wang, Y.Z.; Guo, P. An improved intuitionistic fuzzy interval two-stage stochastic programming for resources planning management integrating recourse penalty from resources scarcity and surplus. J. Clean. Prod. 2019, 234, 185-199. [CrossRef]

48. Huang, G.H.; Loucks, D.P. An inexact two-stage stochastic programming model for water resources management under uncertainty. Civ. Eng. Environ. Syst. 2000, 17, 95-118. [CrossRef]

49. Ji, L.; Sun, P.; Ma, Q.; Jiang, N.; Huang, G.H.; Xie, Y.L. Inexact two-stage stochastic programming for water resources allocation under considering demand uncertainties and response-A case study of Tianjin, China. Water 2017, 9, 414. [CrossRef]

50. Fu, Z.H.; Wang, Y.Q.; Lu, W.T.; Zhao, H.J.; Liu, J.J.; Guo, H.C. An inexact stochastic optimization model for multi-conflict regional water resources allocation in the south-to-north water benefited area. J. Hydroinform. 2018, 20, 946-959.

51. Li, Z.; Li, C.H.; Wang, X.; Peng, C.; Cai, Y.P.; Huang, W.C. A hybrid system dynamics and optimization approach for supporting sustainable water resources planning in Zhengzhou City, China. J. Hydrol. 2018, 556, 50-60. [CrossRef]

52. Meng, C.; Wang, X.L.; Li, Y. An optimization model for water management based on water resources and environmental carrying capacities: A case study of the Yinma River Basin, Northeast China. Water 2018, 10, 565. [CrossRef]

53. Yuan, J.D.; Zhang, N.; Cao, Y.M. Protection and development of tourism resource in Momoge national natural reserve. J. Northeast Norm. Univ. 2005, 37, 109-114.

54. Liu, Y. Study on the Interval Optimization Model of Momoge Wetland Replenishment Scheme under the Constraint of Ecological Benefit. Master's Thesis, Changchun Institute of Technology, Changchun, China, 2017.

55. Millennium, E.A. Ecosystems and Human Well-Being; Island Press: Washington, DC, USA, 2005.

56. Cai, B.F.; Meng, C.; Wang, X.E.; Li, Y. Application of a Fuzzy Two-Stage Chance Constrained Stochastic Programming Model for Optimization of the Ecological Services Value of the Interconnected River System Network Project in the Western Jilin Province, China. Water 2019, 11, 68. [CrossRef]

57. Cui, L.J.; Pang, B.L.; Li, W.; Ma, M.Y.; Sun, B.D.; Zhang, Y.Q. Evaluation of ecosystem services in the Zhalong wetland. Acta Ecol. Sin. 2016, 36, 828-836.

58. Xie, G.D.; Zhang, C.X.; Zhang, M.L.; Chen, W.H.; Li, S.M. Improvement of the evaluation method for ecosystem service value based on per unit area. J. Nat. Resour. 2015, 30, 1244-1252.

59. Debeljak, M.; Džeroski, S.; Jerina, K.; Kobler, A.; Adamič, M. Habitat suitability modelling for red deer (Cervus elaphus L.) in South-central Slovenia with classification trees. Ecol. Modell. 2001, 138, 321-330. [CrossRef] 
60. Shi, W.J. Study on the Changes of Spatial Pattern and the Regulations of Ecological Water Demand in Momoge Wetlands. Master's Thesis, Dalian University of Technology, Dalian, China, 2016.

61. Jiang, H.B.; He, C.G.; Sheng, L.X.; Tang, Z.H.; Yan, T.T.; Zou, C.L. Hydrological modelling for Siberian crane Grus leucogeranus stopover sites in Northeast China. PLoS ONE 2015, 10, e0122687. [CrossRef]

62. Xiao, H.Y. Dynamic of Ecosystem Services of Momoge Nature Reserve and its Drivers of Change. Master's Thesis, Beijing Forestry University, Beijing, China, 2014.

63. Ma, Z.J.; Li, B.; Chen, J.K. Study on the utilization of stopover sites and migration strategies of migratory birds. Acta Ecol. Sin. 2005, 25, 1404-1412.

(C) 2020 by the authors. Licensee MDPI, Basel, Switzerland. This article is an open access article distributed under the terms and conditions of the Creative Commons Attribution (CC BY) license (http://creativecommons.org/licenses/by/4.0/). 